\title{
Corrigendum
}

\section{Resilience, Agency and Coping with Hardship: Evidence from Europe during the Great Recession - CORRIGENDUM}

\section{HULYA DAGDEVIREN AND MATTHEW DONOGHUE}

doi:10.1017/So047279418000624, published by Cambridge University Press 12 October 2018.

Within the original article the following acknowledgement was omitted.

\section{Acknowledgements}

The research on which this article is based received funding from the European Union Seventh Framework Programme, $\mathrm{FP}_{7}$ - SSH-2013-2 Call 5.1.1 'Citizens' Resilience in Times of Crisis' under grant agreement No 613245 RESCuE 'Patterns of Resilience during Socioeconomic Crises among Households in Europe'.

The authors apologise for the oversight.

\section{Reference}

Dagdeviren, H. and Donoghue, M. (2018), 'Resilience, Agency and Coping with Hardship: Evidence from Europe during the Great Recession', Journal of Social Policy, first published online 12 October 2018. doi:10.1017/Soo47279418000624 